\title{
Tecendo a constituição identitária do professor de matemática narrado nos memoriais
}

Vanessa Suligo Araújo Lima vanessa.lima@unemat.br orcid.org/0000-0003-4651-3752 Universidade do Estado de Mato Grosso (Unemat), Barra do Bugres, Mato Grosso, Brasil

Maria Elizabete Rambo Kochhann beterambo@gmail.com orcid.org/0000-0003-0216-7800 Universidade Federal do Sul e Sudeste do Pará (UNIFESSPA), Santana do Araguaia, Pará, Brasil

\section{RESUMO}

Este trabalho é parte de uma pesquisa de mestrado desenvolvida no Programa de PósGraduação Stricto Sensu em Ensino de Ciências e Matemática -PPGEM, da Universidade do Estado de Mato Grosso-UNEMAT, Campus de Barra do Bugres-MT. A investigação teve como objetivo investigar, na formação inicial de Professores, o processo de constituição da identidade docente, que emerge a partir da produção dos Memoriais de Formação dos Licenciandos de Matemática da UNEMAT, Campus de Barra do Bugres - MT; desenvolvidos durante os Estágios Curriculares Supervisionados I e II, realizados nos períodos 2016/02 e 2017/01. A metodologia apoiou-se na abordagem qualitativa, de cunho interpretativo, adotando-se o método (auto)biográfico, com ênfase nas narrativas das histórias de vida, tendo como instrumento de produção de dados os Memoriais de Formação produzidos pelos licenciandos. O trabalho apoiou-se nos contributos teóricos de autores que discutem temas relativos à formação, identidade e Memorial, como Marcelo Garcia (1999), Fiorentini e Castro (2003), Silva, Woodward e Hall (2004), Nóvoa (1992, 2009), Nóvoa e Finger (2014), Passeggi (2006), dentre outros. Os resultados evidenciaram vários elementos em contato, influenciando a constituição da identidade docente dos licenciandos pesquisados. Dentre eles, podemos destacar: família, amigos, escola, contextos sociais, professores; os discursos produzidos pelos licenciandos; marcas (positivas ou negativas) de formação deixadas por professores etc. Concluímos que o Memorial pode ser um valioso instrumento no processo de formação inicial dos licenciandos, podendo contribuir para a formação de sujeitos reflexivos que compreendam seu próprio processo de formar-se professores.

PALAVRAS-CHAVE: Formação Inicial de Professores, Identidade Docente, Memorial de Formação. 


\section{INTRODUÇÃO}

Os a formação inicial de professores tem passado por inúmeras mudanças e tem sido alvo de diversas pesquisas na área de Educação, muitas dessas investigam o processo de constituição da identidade docente dos licenciandos.

Segundo Nóvoa (1992), a formação, entre outros aspectos, pode:

Estimular o desenvolvimento profissional dos professores, no quadro de uma autonomia contextualizada da profissão docente. Importa valorizar paradigmas de formação que promovam a preparação de professores reflexivos, que assumam a responsabilidade do seu próprio desenvolvimento profissional e que participem como protagonistas na implementação de políticas públicas (NÓVOA, 1992, p. 13).

Entretanto, promover a preparação de professores reflexivos requer instrumentos que possibilitem ao sujeito essa reflexão e autonomia em sua formação, em seu processo de formar-se professor. Assim, as pesquisadoras acreditam que um dos caminhos se dá ao permitir, ao futuro professor, refletir sobre sua história, seus percursos e as experiências vividas.

Nesse sentido, com o intuito de promover essa reflexão, a pesquisa utilizou e investigou os Memoriais de Formação, produzidos pelos licenciandos de Matemática, buscando compreender a constituição da identidade docente dos licenciandos ainda em formação. Acredita-se que o Memorial constitui-se como instrumento de reflexão e prática de autoformação dos futuros professores.

Segundo Passeggi (2010), o Memorial de Formação é um:

Texto acadêmico autobiográfico no qual se analisa de forma crítica e reflexiva a formação intelectual e profissional, explicitando o papel que as pessoas, fatos e acontecimentos mencionados exerceram sobre si. Adota-se a hipótese de que nesse trabalho de reflexão autobiográfica, a pessoa distancia-se de si mesma e toma consciência de saberes, crenças e valores, construídos ao longo de sua trajetória. Nesse exercício, ela se apropria da historicidade de suas aprendizagens (trajeto) e da consciência histórica de si mesma em devir (projeto) (PASSEGGI, 2010, p. 1).

Essa definição conduziu a pesquisa ampliando o desejo de utilizar e investigar o Memorial de Formação, como instrumento de reflexão na formação dos futuros professores, a fim de promover momentos de reflexão, análise e compreensão dos processos de constituição da identidade docente que os licenciandos passam e expressam nas narrativas e escritas de si.

Nesse contexto, a motivação e justificativa para realização da pesquisa surgiu de minhas experiências como licencianda do curso de Licenciatura em Matemática, na Universidade do Estado de Mato Grosso-(UNEMAT), Campus de Barra do Bugres - MT; realizadas a partir da escrita de Memoriais de Formação produzidos durante a disciplina de Estágio Curricular Supervisionado I-(ECS-I), em que foi o primeiro momento que me encontrei como educadora.

Nesse sentido, o problema de pesquisa que buscou-se responder foi: Como se constitui a Identidade Docente emergida a partir da produção de Memoriais de Formação de licenciandos em Matemática da Universidade do Estado de Mato Grosso-(UNEMAT), Campus de Barra do Bugres-MT, desenvolvidos durante os Estágios Curriculares Supervisionados I e II do período de 2016/2 e 2017/01? 
Dessa forma, buscando responder a essa questão, a pesquisa teve como objetivo geral: Investigar, na formação inicial de professores, o processo de constituição da identidade docente, que emerge a partir da produção dos Memoriais de Formação dos licenciandos de Matemática, da Universidade do Estado de Mato Grosso-(UNEMAT), Campus de Barra do Bugres - MT, desenvolvidos durante os Estágios Curriculares Supervisionados I e II, realizados, respectivamente, nos períodos de 2016/02 e 2017/01. Para tal atividade, foram traçados os seguintes objetivos específicos:

- Identificar, nas narrativas escritas, as possíveis marcas/influências deixadas por professores, e como estas estão sendo ressignificadas pelos licenciandos, e os elementos/momentos do processo de constituição da identidade docente, que emergem a partir da produção dos Memoriais.

- Analisar se os Memoriais de Formação podem ser instrumentos de reflexão do processo de formar-se professor, na perspectiva dos licenciandos.

Assim, buscou-se na pesquisa, explorar a constituição da identidade docente, a partir da produção de Memoriais de Formação na formação inicial dos licenciandos.

\section{METODOLOGIA}

A metodologia apoiou-se na pesquisa qualitativa de cunho interpretativo, voltada para o método (auto)biográfico, inserindo-se no gênero das narrativas (auto)biográficas, que adotam as histórias de vida e (auto)biografias dos sujeitos. Isso porque o método (auto)biográfico tem, nas escritas dos sujeitos, o referencial para investigar o objeto de estudo. Este, por sua vez, foi analisado a partir da produção dos Memoriais de Formação, com características que possibilitam o desenvolvimento de uma investigação dessa natureza.

Segundo Bogdan e Biklen (1994), a abordagem da investigação qualitativa exige que o mundo seja examinado como ideia de que nada é trivial, que tudo tem potencial para constituir uma pista que nos permita estabelecer uma compreensão mais esclarecedora do nosso objeto de estudo. Nesse caso, pequenos elementos puderam apresentar pistas ou indícios de elementos/momentos de constituição da identidade docente expressos nos Memoriais.

O método utilizado na pesquisa foi o autobiográfico, com ênfase nas técnicas de narrativas das histórias de vida, a partir dos Memoriais de Formação, pois acreditou-se- serem apropriados para o desenvolvimento da investigação, que consolida a análise das experiências de formação vivenciadas pelo sujeito, uma vez que, conforme salienta Moita (2007, p. 116), “[..] só uma história de vida põe em evidência o modo como cada pessoa mobiliza os seus conhecimentos, os seus valores, as suas energias, para ir dando forma à sua identidade, num diálogo com os seus contextos".

Segundo Portugal (2016):

A Pesquisa (auto)biográfica vem se constituindo e se consolidando, ao longo das últimas décadas, como uma abordagem da pesquisa qualitativa, bastante utilizada no contexto da formação e da profissão docente, no cenário nacional e internacional, caracterizando-se como uma metodologia de investigação, 
ao desvendar modos singulares de investigar a formação, a prática docente (docência), a vida, os saberes e a carreira/trajetória profissional dos professores (PORTUGAL, 2016, p. 211).

Diante da consolidação das pesquisas que utilizam o método (auto)biográfico, compreendeu-se esse método como possibilidade de compreensão dos percursos de formação e das experiências vividas, no contexto de formação de professores.

Nesse cenário, as compreensões da pesquisa, no âmbito da investigação, apoiaram-se nas ideias de autobiografia apresentadas por Nóvoa e Finger (2014) e Passeggi (2008), entre outros.

Para Nóvoa e Finger (2014) a (auto)biografia se apresenta como uma das alternativas de formação: os sujeitos serão estimulados a autoformar-se, à medida que forem explicitando suas trajetórias de vida. E, Passeggi (2008. p. 27) complementa que autobiografar é "[...] aparar para si com suas próprias mãos", em que aparar é ajudar a nascer no sentido de "[...] cuidar de si e renascer de outra maneira pela mediação da escrita".

Logo, optou-se pela escolha desse método, devido à possibilidade de compreensão da formação do sujeito que, ao narrar suas experiências e histórias de vida em Memoriais, faz uma reflexão sobre os percursos vividos que podem apresentar e instigar elementos/momentos de constituição da identidade docente.

Dessa forma, investigou-se na pesquisa os percursos de formação vividos e narrados pelos licenciandos sobre suas histórias de vida, na perspectiva dos próprios sujeitos, autores dessa formação. Assim, para analisar esses percursos de formação, a pesquisa utilizou, como instrumento de produção de dados, os Memoriais de Formação, produzidos pelos licenciandos do Curso de Licenciatura em Matemática da UNEMAT de Barra do Bugres-MT, durante as disciplinas de Estágios Curriculares Supervisionados - (ECS) I e II, realizadas, respectivamente, entre os períodos de 2016/02 e 2017/01, os mesmos continham eixos orientadores para a escrita.

Segundo Passeggi (2003, p. 6), o "Memorial é um ato de linguagem que se materializa sob a forma de narrativa (auto)biográfica". O sujeito, ao escrever/narrar, mobiliza processos cognitivos, socioafetivos e metacognitivos para dar unidade ao que relata. Essa mesma dimensão contribui para o redimensionamento das representações de si e da trajetória percorrida em sua vida.

Assim, a pesquisa buscou explorar a constituição da identidade docente emergida a partir da produção de Memoriais de Formação dos licenciandos, no sentido de perceber que indícios podem ser encontrados nas narrativas autobiográficas da história de vida e de formação desses sujeitos.

Os sujeitos que compuseram esta pesquisa foram, inicialmente, 6 (seis) licenciandos do Curso de Licenciatura em Matemática da UNEMAT de Barra do Bugres-MT. Esses licenciandos produziram o primeiro Memorial de Formação, durante a disciplina de ECS-I, realizada no período 2016/02. Destes, apenas 5 (cinco) deram continuada ao estágio e produziram o segundo Memorial no ECS-II, realizado no período de 2017/01. Os licenciandos foram orientados e acompanhados durante a realização dos dois estágios. 
A análise dos dados foi realizada pelas pesquisadoras por meio da abordagem qualitativa, com base no método autobiográfico das narrativas da história de vida, que consolida a análise de cunho interpretativo das experiências de formação dos sujeitos. Considerou-se que a utilização desse método produziu uma quantidade considerada de dados qualitativos.

Por fim, para preservar a identidade dos licenciandos participantes, foi utilizado um pseudônimo escolhido por eles próprios, de acordo com sua história de vida e formação, conforme apresentado a seguir:

Figura 1: Quem são os licenciandos que produziram o Memorial-I ?

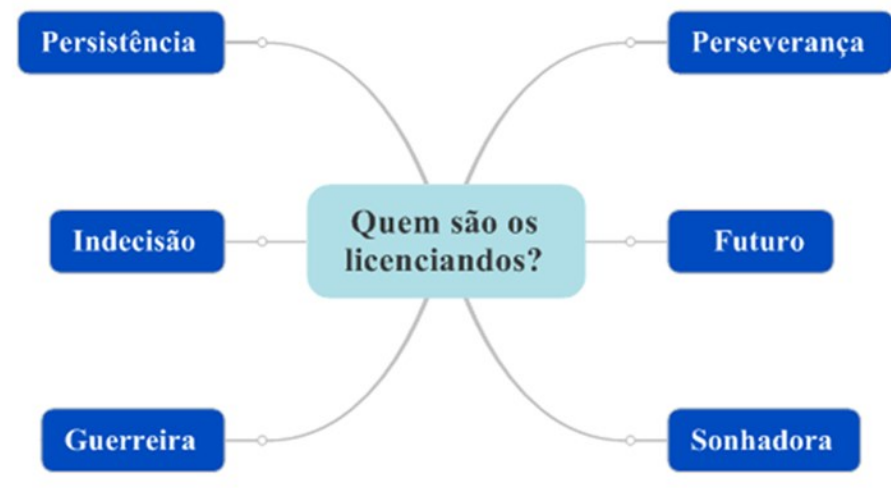

Fonte: Autoria própria (2017).

Destes licenciandos apresentados, apenas Indecisão não participou da segunda análise do Memorial.

Assim, considerou-se na pesquisa que pelos Memoriais de formação dos licenciandos investigados pudessem encontrar pistas e indícios que permitiram compreender o processo de constituição da identidade docente dos mesmos.

Portanto, o Projeto de pesquisa foi encaminhado ao Comitê de Ética da UNEMAT, inicialmente como o nome Ser ou não Ser: o processo de formar-se professor de Matemática narrado nos Memoriais, em 14/09/2016 pelo número do protocolo 60187116.6.00005166 e aprovado na data do dia 22/10/2017.

\section{RESULTADOS E ANÁLISES}

Considerando o instrumento de pesquisa utilizado, procurou-se na pesquisa analisar os licenciandos em sua trajetória de vida e seus processos de formação, expressos nos Memoriais, entendendo como um "movimento" de análise para compreender o processo de constituição da identidade docente.

Nesse movimento de análise, encontrou-se vários elementos de formação que emergiram a partir da produção dos Memoriais de Formação dos licenciandos do curso de Matemática da UNEMAT, Campus de Barra do Bugres-MT. Acredita-se que esses indícios de constituição da identidade docente puderam fazer compreender melhor esse processo de formar-se professor, mostrando algumas pistas que deram alguns caminhos. 
Começando o movimento de análise, lançou-se um olhar subjetivo sobre o primeiro Memorial de Formação produzido pelos licenciandos, fazendo um exercício reflexivo sobre suas narrativas, conforme a orientação da escrita, ou seja, dividida por eixos, sendo eles:

- Eixo 1: Trajetória de Vida Pessoal e Familiar;

- Eixo 2: Trajetória da Educação Básica; e,

- Eixo 3: Trajetória do formar-se professor de Matemática.

Com relação ao Eixo 1: Trajetória de Vida Pessoal e Familiar.

Esse eixo apresentou elementos de formação relacionados com a formação de vida pessoal e familiar dos licenciandos. De modo geral, os licenciandos evidenciam uma infância feliz e marcada pelo prazer de ir à escola, de aprender, ensinar e interagir com os colegas, que compreendemos como elementos de formação da identidade pessoal do sujeito sendo produzida nas relações. Podemos verificar isso na sequência discursiva de Indecisão (2016) que evidencia esse gostar de ir para a escola, quando narra que:

[Narrativa 1]: Mamãe fala que eu sempre gostei da escola e chorava quando ficava doente e não podia ir, até as brincadeiras lembrava a escola, gostava de brincar de escolinha sempre ensinando os amiguinhos (INDECISÃO, 2016).

Compreendeu-se que o ato de ensinar e aprender já se fazia presente em sua infância, pois a licencianda gostava, desde cedo, desse processo de ensino e aprendizagem e do ato de ensinar seus colegas na escola.

Entretanto, apesar dos relatos de uma infância feliz, os licenciandos também evidenciaram marcas negativas relacionadas a esse período, conforme pode-se verificar na sequência discursiva de Guerreira (2016), quando evidencia que:

[Narrativa 2]: Tínhamos uma infância com certa liberdade, mas também com traumas, meu pai era alcoólatra, bebia quase todos os dias, era difícil a noite que ele não bebia, era agressivo com minha mãe, mulher guerreira, tenho na lembrança o que nos consolava era saber que logo amanheceria e voltaríamos a ter a liberdade pelo menos no decorrer do dia estaríamos soltos, iriamos para escola estudar, aprender, brincar, conviver e conversar com os colegas, rir, e assim estaríamos livres de ver nosso pai alcoolizado.(GUERREIRA, 2016)

Compreendeu-se pela sua narrativa que a escola era um dos refúgios de Guerreira, que sentia liberdade em estudar, em conhecer o novo e interagir com outros, que na escola ela sentia liberdade quando aprendia e se relacionava com os colegas, e que mesmo com as experiências traumatizantes de sua formação, isso a constitui enquanto uma aluna que gostava de estudar.

De forma geral, entendeu-se que todas essas "experiências" vivenciadas pelos licenciandos, influenciaram a constituição de suas identidades, produzindo suas identidades. Pois, para Larrosa (2002, p. 27), a "experiência" pode ser compreendida como "aquilo que nos acontece", "o que nos toca", e que "os sentidos que damos a esse acontecido em nós" produzem também a nossa identidade.

Nesse cenário, compreendeu-se que as relações com a família e com os contextos sociais; e as representações e produção dos sentidos dessas 
experiências, influenciaram a constituição de quem estes sujeitos se formaram e estão se formando, e entendeu-se esse movimento de constituir-se, nessa interação da pessoa e os contextos, e que tais contextos produzem identidades a partir do sentidos e significados que cada indivíduo atribui ao que o acontece, ao que o toca, ao que o forma e o transforma de alguma forma, produzindo assim novas identidades.

Com relação ao Eixo 2: Trajetória da Educação Básica.

Para melhor compreensão da trajetória da Educação Básica dos licenciandos, foi subdividido esse eixo em duas etapas: Ensino Fundamental e Ensino Médio.

Com relação ao Ensino Fundamental, o que emergiu das narrativas dos licenciandos foi que eles tiveram marcas positivas e negativas de professores que os influenciaram em sua formação. Sobre as positivas, alguns professores, em especial, destacam-se aqueles que os ensinaram a gostarem de estudar, a gostarem da disciplina de Matemática, e a quererem se tornar um professor de Matemática. Pode-se verificar alguns desses aspectos na narrativa de Perseverança (2016), quando relata que:

[Narrativa 3]: Na 8a série tive a oportunidade de estudar com o Professor Edvagner de matemática, a sua simplicidade, a forma com que ele dava aulas, transmitia o conteúdo com mais clareza, de fácil entendimento, seu jeito de vir até mim tirar minhas dúvidas a respeito do conteúdo, são pontos que me fizeram despertar o interesse pela matemática e por ser um professor de matemática. (PERSEVERANÇA, 2016)

Compreendeu-se que esse professor teve grande influência na formação de Perseverança, despertando-Ihe, inicialmente, o gosto pela Matemática e por ser um professor de Matemática. Assim, acredita-se que esses são alguns elementos/pistas de como a identidade desse licenciando começou a ser constituída na escolaridade, na relação com o outro, neste caso, o professor.

Nesse movimento de compreender como o outro se constitui, verificou-se na pesquisa, a partir das análises dos excertos, que emergem nas narrativas dos licenciandos o elemento "influência do professor", em seu processo de formação, em que alguns evidenciam marcas negativas que ainda não foram ressignificadas, e outros evidenciando marcas positivas que influenciaram a constituição de suas identidades, bem como na direção de uma identidade docente sendo constituídas. Essa construção pode ser compreendida, nas palavras de Nóvoa (1992), quando evidencia que:

A identidade não é um dado adquirido, não é um produto. A identidade é um lugar de lutas e conflitos, é um espaço de construção de maneiras de ser e estar na profissão. Por isso, é mais adequado falar em processo identitário, realçando a mescla dinâmica que caracteriza a maneira como cada um se sente e se diz professor (NÓVOA, 1992, P. 10).

Nesse sentido, a pesquisa acredita que a constituição da identidade docente passa por processos em que cada sujeito produz um sentido, um significado, e que essa constituição se inicia na própria maneira como o sujeito se sente ou se diz professor, conforme evidenciado pelo autor e expresso nas palavras da licencianda, quando enuncia que sentiu a vontade de ser professora, ainda no Ensino Fundamental, pelo fato de ver a maneira como era o seu próprio professor. 
Esses elementos presentes no discurso da licencianda, fizeram as pesquisadas compreenderem que, nesse período, a identidade docente já vem sendo constituída, quando a licencianda se sente e se diz querer ser uma professora de Matemática.

Em relação à etapa do Ensino Médio, percebeu-se que os licenciandos narram que passaram por várias dificuldades, pois era outra realidade, outro comprometimento. Tinham de ser mais responsáveis com as atividades escolares, e, ainda, alguns deles tinham de trabalhar e estudar ao mesmo tempo. Os licenciandos ainda relatam que era um período marcado pela preparação para ingressar em uma universidade e essa preparação, segundo Perseverança (2016), o fazia "ter mais vontade de entrar em alguma Universidade."

Foi nesse período do Ensino Médio que os licenciandos começaram a traçar alguns caminhos a percorrer na trajetória educacional no Ensino Superior, cada um se formando, se transformando e se constituindo de uma forma singular.

Percebeu-se assim, que no Ensino Médio, período de preparação para o ingresso no Ensino Superior, a maioria dos licenciandos narra que não queria ser professor, ou, não sabia o que queria ser. Apenas 2 (duas) licenciandas investigadas relatam que queriam ser professoras de Matemática, pela influência de professores de Matemática e porque já haviam se identificado com a profissão de ensinar. $O$ quadro a seguir mostra de forma mais clara essa afirmação:

Quadro 1 - Quadro de escolhas do Ensino Médio

\begin{tabular}{|c|c|}
\hline Licenciandos & Escolhas do Ensino Médio \\
\hline Perseverança & Gostava de matemática, mas, queria ser engenheiro civil. \\
\hline Indecisão & Queria ser médica, por influência da mãe. \\
\hline Guerreira & $\begin{array}{c}\text { Não sabia o que queria ser, mas queria continuar estudando, um } \\
\text { dos motivos pela motivação de seu diretor e professor de } \\
\text { matemática. }\end{array}$ \\
\hline Persistência & $\begin{array}{c}\text { Tinha afinidade com a matemática, gostava de estudar, mas não } \\
\text { sabia o que queria ser, mas queria cursar o ensino superior. }\end{array}$ \\
\hline Sonhadora & $\begin{array}{c}\text { Já não tinha dúvidas que queria ser professora de matemática, } \\
\text { pela influência de professores de matemática. }\end{array}$ \\
\hline \multirow[t]{2}{*}{ Futuro } & $\begin{array}{l}\text { Decidiu ser professora de matemática, pela influência de } \\
\text { professores de matemática }\end{array}$ \\
\hline & Fonte: Autoria própria (2016). \\
\hline
\end{tabular}

Percebeu-se assim que, embora a maioria dos licenciandos ainda não queiram ser professores, duas licenciandas já tinham decido pela profissão de professoras de Matemática, influenciadas pelos professores, em especial de Matemática, que tiveram ao longo de sua formação. O que foi compreendido como elementos importantes no processo de constituição da identidade docente dos sujeitos.

Dessa forma, acredita-se que essas identidades estão sendo produzidas dentro dos e nos discursos em que as licenciandas se posicionam, pois conforme destaca Woodward (2004, p. 55), "as posições que assumimos e com as quais nos identificamos constituem nossas identidades". Assim, estas identidades vão sendo produzidas dentro dos e nos discursos, bem como nas relações com o outro, neste caso, o professor de Matemática, em cuja imagem positiva se espelham e a partir da qual desejam tornar-se professoras. 
Com relação ao Eixo 3: Trajetória do formar-se professor de Matemática.

Nessa etapa de início do Ensino Superior, percebeu-se que alguns licenciandos começam a mudar as escolhas de sua profissão, para a de professores de Matemática, em sua maioria, influenciados por professores, em especial de Matemática, que tiveram no Ensino Fundamental e Médio. E, as 2 (duas) licenciandas, que queriam ser professoras de Matemática, mantiveram suas decisões, também influenciadas pelos professores ao longo de suas formações. Podemos verificar no quadro a seguir:

Quadro 2 - Mudanças de escolha para o Ensino Superior.

\begin{tabular}{|c|c|}
\hline Licenciandos & Mudanças de escolha \\
\hline Perseverança & $\begin{array}{l}\text { Fez engenharia civil por } 4 \text { semestres e percebeu que não era o } \\
\text { que queria, trocando de curso para o de matemática, devido à } \\
\text { influência de um antigo professor de matemática. }\end{array}$ \\
\hline Indecisão & $\begin{array}{l}\text { Queria ser médica, mudou de opção para engenharia civil, por } \\
\text { medo de não passar e também por influência de sua professora } \\
\text { de matemática e amiga. fez matemática. posteriormente, } \\
\text { complementou com farmácia, relatando ser suas duas paixões e, } \\
\text { embora queira ser professora, ainda não sabe que área seguir. }\end{array}$ \\
\hline Guerreira & $\begin{array}{l}\text { Queria continuar estudando, mas casou-se e seu marido não a } \\
\text { deixou estudar, ficando } 18 \text { anos fora da sala de aula. após a } \\
\text { separação, decidiu fazer matemática pela afinidade, por ser um } \\
\text { bom campo de trabalho e pela influência do professor e diretor. }\end{array}$ \\
\hline Persistência & Decidiu fazer matemática, pois tinha afinidades com a disciplina. \\
\hline Sonhadora & $\begin{array}{l}\text { Manteve a decisão de ser professora de matemática, por } \\
\text { influência de professores de matemática. }\end{array}$ \\
\hline \multirow[t]{2}{*}{ Futuro } & $\begin{array}{l}\text { Manteve a decisão de ser professora de matemática, por } \\
\text { influência de professores de matemática }\end{array}$ \\
\hline & Fonte: Autoria própria (2017). \\
\hline
\end{tabular}

Assim, nesse exercício subjetivo percebeu-se que, nessa etapa de início do Ensino Superior, alguns licenciandos começaram a mudar as escolhas de sua profissão, para a de professores de Matemática, influenciados por professores de Matemática que tiveram no Ensino Fundamental e Médio, e as 2 (duas) licenciandas que queriam ser professoras de Matemática mantiveram sua decisão, que também foi influenciada pelos professores, em especial de Matemática, ao longo de sua formação.

De acordo com Marcelo Garcia (2009, p. 4), "é preciso compreender o conceito de identidade como uma realidade que evolui e se desenvolve, tanto pessoal, quanto coletivamente", pois não podemos possuir a identidade. Ela vai sendo desenvolvida durante a vida, não sendo algo fixo e determinado para uma pessoa, mas um movimento que ocorre nas relações com o outro e com os contextos onde os sujeitos se inserem.

O que complementa Hall (2004, p. 108), quando afirma que a identidade tem a ver nem tanto com a questão "quem nós somos?", mas muito mais com as questões de "quem nós podemos nos tornar?", sinalizando que o sujeito pode, ao questionar-se desse ponto de vista, produzir novas identidades.

Dessa forma, o que se percebeu é que os licenciandos começam a querer se tornar professores de Matemática, em especial, pela influência exercida pelos 
professores de Matemática que tiveram ao longo de história de vida e de formação. Isso nos auxilia a compreender melhor os elementos que influenciam a constituição do ser professor.

Compreendeu-se, assim, que os professores começam a marcar a vida dos licenciandos e que essa influência pode ser um dos elementos que nos deu pistas, elementos de constituição da identidade docente dos futuros professores, pois, ao olharam para seus professores, almejam tornarem-se como eles. Conforme destaca as pesquisas investigadas por Marcelo Garcia (2009, p. 114), "a identidade profissional envolve tanto a pessoa, como o contexto", e portanto, o contexto de formação no qual os sujeitos estão inseridos sofre influência da família, dos contextos sociais, dos professores e de sua história de vida e formação.

Com relação a que identidade os licenciandos procuram constituir, de modo geral, pode-se compreender este aspecto presente na narrativa de Persistência (2016), quando narra que "como identidade docente procurar sempre ser uma ótima educadora. Eu analiso esse processo de ser um professor de matemática em me dedicar ao máximo de mim e me aperfeiçoar sempre para levar o máximo de conhecimento aos meus alunos" (PERSISTÊNCIA, 2016).

Neste sentido, entende-se que a constituição da identidade dos licenciandos possa ser compreendida, conforme evidencia Marcelo Garcia (2009, p. 112), quando afirma que "a identidade não é algo que se possua, mas sim algo que se desenvolve durante a vida". Assim, percebeu-se que os licenciandos estão produzindo e desenvolvendo uma identidade docente, de modo geral, ao longo de sua formação, e que ela se relaciona com os aspectos da influência da família, dos amigos, dos professores que tiveram, em especial os de Matemática, e dos contextos nos quais estão ou estiveram inseridos, formando uma teia que contribui em sua formação e desenvolvimento e produção de suas identidades.

Desse modo, compreendeu-se que os licenciandos procuram constituir uma identidade docente que contribua para a formação de seus alunos, que possam se dedicar para realizar um bom trabalho docente

Sonhadora (2016), ainda complementa que, com a orientação de sua professora de estágio I, conseguiu compreender melhor o sentido do Memorial de Formação:

\footnotetext{
[Narrativa 4]: Antes eu via como um documento que iria contar apenas minha história pessoal, porém não iria me ajudar na minha formação, mas, agora vejo que o Memorial é um instrumento para a reflexão da constituição da minha identidade docente, pois ao reescrevê-lo pude perceber traços de minha formação que passaram despercebidos esses anos todos e inclusive na primeira vez que o escrevi, e que influenciaram minha escolha do curso de licenciatura em matemática. (SONHADORA, 2016)
}

Pela narrativa desta licencianda, verificou-se que escrever e reescrever as narrativas autobiográficas, expressas no Memorial, evidenciaram para ela aspectos de sua formação que antes haviam passado despercebidos, mas que influenciam na professora que ela quer se tornar.

De forma geral, todos os licenciandos na produção dos Memoriais, destacaram a importância da produção destes instrumentos de reflexão para a constituição da identidade docente. 
Partindo desse pressuposto, compreendeu-se os Memoriais de Formação como:

Narrativas que carregam sentimentos, emoções, vivências, trajetórias que são constitutivas dos sujeitos, estudantes e/ou profissionais em formação. Caracteriza-se como uma escrita reflexiva de processos experienciados, sendo possível vislumbrar como a pessoa se mostra ao outro nas diferentes dimensões: pessoal, social, formativa e profissional. (ROCHA; ANDRÉ, p. 8283).

Sob essa ótica, a narrativa pode ser compreendida como uma atividade formadora para constituição da identidade docente.

Dessa forma, compreendeu-se que a Identidade Docente, não é algo pronto e acabado; fixo e impossível de mudança, mas como algo fluente, em constante desenvolvimento, mudança e transformação. Ela pode ainda ser produzida ao longo da vida do sujeito, no contato com as outras identidades produzidas pelos sujeitos e por seus discursos e práticas discursivas, pelas representações e significados que os sujeitos fazem daquilo que os acontece e que contribuem para "quem eles querem se tornar".

Nesse movimento cuidadoso e atencioso de análise, acreditou-se que o Memorial pode ser um valioso instrumento utilizado no processo de formação e constituição da identidade docente dos licenciandos. Isso requer, por um lado, uma boa orientação por parte dos professores formadores e, por outro, um mergulho profundo, por parte do licenciando, na sua história de vida e formação, em busca de elementos que o formem e o transformem, mas que, acima de tudo, possibilitem a reflexão dos percursos vividos e do processo de formarem-se, constituírem professores de Matemática, produzindo, assim, também, suas identidades.

Com relação a análise do Memorial de Formação II, produzido pelos licenciandos de Matemática, durante o ECS-II, realizado no período de 2017/02, lançou-se novamente um olhar subjetivo sobre o mesmo refletindo sobre suas narrativas, conforme a orientação da escrita, ou seja, dividida por eixos, sendo eles:

- Eixo 1: Como estou percebendo meus estudos, as dificuldades, os avanços e recuos?

- Eixo 2: Qual é a posição social e profissional do professor na atualidade? E o que o Estágio tem significado?

- Eixo 3: Como analiso a construção de minha identidade docente? E, a produção dos Memoriais?

Com relação ao Eixo 1, como os Licenciandos estão percebendo seus estudos, suas dificuldades, avanços e recuos; eles evidenciam que estão tendo dificuldades para conseguir conciliar trabalho, família e faculdade e apontam, como disciplinas mais difíceis, de modo geral, a Álgebra linear, Estruturas Algébricas, Cálculo, Fundamentos da Matemática Elementar, Geometria e Análise. Contudo, relatam que, apesar destas serem disciplinas mais difíceis, também têm dificuldade com disciplinas teóricas, conforme narra Sonhadora (2017): “A disciplina de Cálculo mesmo sendo mais difícil, tenho mais facilidade do que as disciplinas teóricas [...] creio eu por não ter muito o hábito da leitura". 
Assim, compreendeu-se que mesmo os licenciandos apontando as disciplinas de Matemática Formal como as mais difíceis do curso, eles desabafam que sentem dificuldades com disciplinas de Educação, de modo geral, por não terem o hábito da leitura e da escrita, uma característica do perfil do licenciando de Matemática, e por não terem a prática de ensino da Matemática. Logo, analisamos a importância de atividades voltadas para atender essas dificuldades, visando à formação de um sujeito "crítico" e "reflexivo".

Nóvoa (1992) também defende que a formação deve estimular essa perspectiva crítico-reflexivo, para que os sujeitos se tornem autônomos em sua formação, consequentemente, possibilitando facilitar sua auto-formação. Sobre isso, o autor destaca que:

É importante estimular junto aos futuros professores e nos anos iniciais de exercício profissional, práticas de auto-formação, momentos que permitam a construção de narrativas sobre suas próprias história de vida pessoal e, profissional. E refiro-me à necessidade de elaborar um conhecimento pessoal (um auto- conhecimento) no interior do conhecimento profissional e de captar (capturar) o sentido de uma profissão que não cabe apenas numa matriz técnica ou científica. Toca-se aqui em qualquer coisa indefinível, mas que está no cerne da identidade docente. (NÓVOA, 2009, p. 39)

Nesse sentido, a formação pode oferecer estratégias que contribuam com essa perspectiva crítico-reflexiva e promova dinâmicas de autoformação como raiz da constituição da identidade docente. Acredita-se que a produção de Memoriais pode ser uma delas, pois busca levar o licenciando a refletir sobre sua própria história de vida, possibilitando-lhe ressignificá-la e autoformar-se por sua trajetória vivida.

Com relação ao Eixo 2, que questiona qual é a posição social e profissional do professor na atualidade? E o que os Estágio tem significado para os licenciandos? O que emerge das narrativas dos licenciandos é que o professor da atualidade deveria ser um professor "flexível" que buscasse "novas metodologias" para o ensino da Matemática e que construísse "conhecimento junto com os alunos".

De acordo com Nóvoa (1992, p.14), o construir este conhecimento junto com o aluno "não se trata de mobilizar a experiência apenas numa dimensão pedagógica, mas também num quadro conceitual de produção de saberes." E, por isso, enfatiza a necessidade da "criação de redes de (auto)formação participada que permitam compreender a globalidade do sujeito, assumindo a formação como um processo interativo e dinâmico" (NÓVOA, 1992, p. 14). Enfatizando, ainda, que essa troca de experiências consolida espaços de formação mútua, que contribuem para o formador e para o formando, e esta troca se faz necessária na formação.

Emergiu ainda das narrativas dos licenciandos que, mesmo percebendo atualmente que, muitos professores encontram-se desmotivados com a indisciplina dos alunos e a falta de valorização de seu trabalho, ainda há aqueles motivados no exercício da profissão. Esses são "modelos de professores" que os licenciandos querem seguir, pois são exemplos de professores que se "comprometem" com o processo de ensino e de aprendizagem de seus alunos.

Neste sentido, analisou-se que os licenciandos apresentam "modelos de professores" que querem seguir e vão, assim, constituindo suas identidades. Pois, de acordo com Hall (2004), a identidade: 
[...] tem a ver entretanto da linguagem e da cultura da produção 'não daquilo que nós somos', mas 'daquilo no qual nos tornamos'. Tem a ver não tanto com as questões "quem nós somos" ou "de onde nós viemos", mas muito mais com as questões de "quem nós podemos nos tornar", "como nós temos sido representados" e "como essa representação afeta a forma como nós podemos representar a nós mesmos" (HALL, 2004, p. 108).

Percebeu-se que a forma como os licenciandos representam esses professores como "modelo de professores" que querem seguir, vão produzindo suas identidades. Esse fato os auxilia a se transformarem em quem eles querem se tornar, neste caso, professores de Matemática.

Já com relação ao significado do estágio para os licenciandos, as narrativas revelaram que o estágio é um momento importante uma vez que articula teoria e prática e proporciona a vivência da experiência docente, que os coloca em confronto com a decisão de ser ou não ser professores, bem como de analisar a prática docente do professor, necessária à futura caminhada profissional dos licenciandos. Podemos perceber a importância desse momento na formação, nas palavras de Futuro (2017), quando evidencia que a disciplina de Estágio -II proporcionou,

[Narrativa 5]: [...] um momento de reflexão, hoje consigo analisar o quanto já construí, como futura professora. Sei que nunca vou estar pronta, mas já achei o caminho para trilhar em busca do eu professor, esta auto-avaliação não serve apenas para mensurar os meus objetivos alcançados, mas também para avaliar o meu preparo quanto ser professora. Pois, o Professor é aquele que transmite alguma coisa a alguém, portanto a relação dos professores com os saberes que ensinam é fundamental para sua identidade profissional. (FUTURO, 2017)

Percebeu-se que esse momento de estágio tem contribuído não apenas com a formação de modo geral, mas também com a construção da identidade profissional dos licenciandos, na medida que proporciona a vivência da experiência docente, articulando teoria e prática, bem como o desenvolvimento de saberes necessários à prática docente.

Assim, acredita-se que a identidade docente vai sendo construída dentro do e no discurso da licencianda que, apesar de dizer não ter certeza de querer ser professora, afirma acreditar que será uma grande professora. Isso nos leva a compreender uma identidade sendo constituída, de uma professora calma, com domínio de sala, expresso na representação de si em seu discurso. Assim, as representações produzidas dentro dos e nos discursos, "[...] constroem os lugares a partir dos quais os indivíduos podem se posicionar e a partir dos quais podem falar" (WOODWARD, 2004, p. 17), e a licencianda fala de como pode ser uma boa professora pelas suas características apresentadas no ato de ensinar, evidenciando o que ela pode tornar-se.

Compreendeu-se também, conforme apresenta Nóvoa (1992), que:

A identidade não é um dado adquirido, não é uma propriedade, não é um produto. A identidade é um lugar de lutas e conflitos, é um espaço de construção de maneiras de ser e estar na profissão. Por isso, é mais adequado falar em processo identitário, realçando a mescla dinâmica que caracteriza a maneira como cada um se sente e se diz professor (NÓVOA, 1992, p.10). 
Assim, como o licenciando se diz professor dentro dos e nos discursos vai, aos poucos, constituindo também sua identidade, tornando-o professor.

Com relação ao Eixo 3, como os Licenciandos analisam a construção de sua identidade como aluno, apresentaremos no quadro, a seguir, de forma geral, o que suas narrativas evidenciam:

Quadro 3 - Narrativas dos licenciandos sobre como analisam a construção de sua identidade como aluno.

\begin{tabular}{|c|c|}
\hline Licenciandos & Mudanças de escolha \\
\hline Perseverança & $\begin{array}{l}\text { No Estágio eu me percebo na descoberta do ser professor...sei e } \\
\text { o curso irá me proporcionar coisas boas e abrir muitas portas na } \\
\text { área de educação como professor de matemática...hoje tenho a } \\
\text { convicção de que fiz a escolha certa quando escolhi o curso de } \\
\text { matemática para ser professor. }\end{array}$ \\
\hline Indecisão & $\begin{array}{c}\text { Falar da minha trajetória acadêmica, da formação e da } \\
\text { experiência discente me remete a falar de memórias. Estas por } \\
\text { sua vez, remetem ao passado e dele emergem imagens, } \\
\text { emoções, palavras. O processo de ensino e aprendizagem } \\
\text { proporcionado pelos professores, as influências recebidas para } \\
\text { construção da pessoa e da profissional que hoje sou, e o "desejo } \\
\text { de tornar-me professora." }\end{array}$ \\
\hline Guerreira & $\begin{array}{c}\text { [...] não sei se quero ser professora... mas tiveram momentos que } \\
\text { vivi no estágio que percebi que com meu jeito de ser posso ser } \\
\text { uma boa professora. }\end{array}$ \\
\hline Persistência & $\begin{array}{c}\text { A experiência de estágio me confirmou mais uma vez que estou } \\
\text { na direção certa..., mesmo sabendo que tenho uma longa } \\
\text { caminhada a seguir. }\end{array}$ \\
\hline Sonhadora & $\begin{array}{l}\text { Hoje vejo com mais clareza as direções que tomei desde o } \\
\text { primeiro dia na faculdade até agora, o quanto eu cresci, } \\
\text { amadureci, o quanto aprendi. Hoje sei o caminho a seguir, e o } \\
\text { melhor sei por onde começar. }\end{array}$ \\
\hline Futuro & $\begin{array}{l}\text { O Estágio eu me percebo na descoberta do ser professor...sei e o } \\
\text { curso irá me proporcionar coisas boas e abrir muitas portas na } \\
\text { área de educação como professor de matemática...hoje tenho a } \\
\text { convicção de que fiz a escolha certa quando escolhi o curso de } \\
\text { matemática para ser professor. }\end{array}$ \\
\hline
\end{tabular}

Pode-se analisar que dos 5 (cinco) licenciandos, apenas uma ainda declara não ter certeza sobre querer ser professora de Matemática, contudo revela em seu discurso que acredita que pode ser uma boa professora. Acredita-se que esse elemento seja um indício, uma pista, um elemento que evidencie também uma identidade docente sendo constituída. Para os outros licenciandos, a formação, em especial o estágio, vieram a contribuir para articular a teoria e prática, possibilitando a vivência de experiências docentes, e contribuindo em sua formação e constituição da identidade docente.

Nesse sentido, de acordo com Marcelo Garcia (2009), compreende-se que: 
caracteriza como um processo evolutivo, um processo de interpretação de si mesmo como pessoa dentro de um determinado contexto (MARCELO GARCIA, 2009, p. 112).

Portanto, para compreender a constituição da identidade docente é importante compreender a trajetória vivida pelo sujeito, ao longo de sua formação, entendendo que ela não se constitui apenas quando o sujeito ingressa na formação inicial, mas que, durante essa formação, os instrumentos utilizados e os momentos vivenciados, em especial, no estágio podem contribuir para que o sujeito vá, aos poucos, se descobrindo ou se reafirmando professor.

Já em relação à produção dos Memoriais, os licenciandos narram que a escrita deles possibilitou-Ihes refletir sobre a formação, a constituição da identidade docente, bem como, os Memoriais e influenciaram em quem estão se tornando, se transformando, propiciando-Ihes ainda a reflexão sobre seu percurso de vida e formação. Podemos ver um momento desses relatos na narrativa apresentada a seguir:

De acordo com Perseverança (2017), ao produzir o Memorial:

[Narrativa 6]: Revivi minha trajetória até na Universidade e hoje tenho a convicção que fiz a escolha certa quando escolhi cursar Matemática, tenho certeza e consciência que este processo que vai durar quatro anos dentro da faculdade, vai ser apenas uma das primeiras etapas, e que as próximas etapas que virão serão cada vez maiores, pois a profissão do ser professor tem desafios diários. (PERSEVERANÇA, 2017)

Pode-se perceber que produzir o Memorial levou a licencianda a refletir criticamente sobre a formação, sobre a escolha de ser professor e se auto-avaliar em sua trajetória educacional.

Nesse sentido, apoiados em Passeggi (2008), que compreende o Memorial como um gênero acadêmico autobiográfico, acredita-se também que esse instrumento permite que o autor se (auto)avalie, tecendo reflexões críticas sobre seu percurso intelectual e profissional e que essa narrativa pode clarificar experiências significativas para sua formação. Assim, conforme a narrativa da licencianda, percebemos que produzir o Memorial pode contribuir para ter consciência da escolha de querer ser professor e auxiliar na construção de sua identidade docente, na medida em que reflete sobre o professor que deseja tornar-se.

Acredita-se assim, que as reflexões realizadas pelos licenciandos, e aqui apresentadas, podem contribuir para a compreensão de suas identidades que vão sendo produzidas dentro dos e nos discursos. Compreendemos ainda que produzir um Memorial é um exercício sistemático de revistar a própria história, refletindo sobre ela, compreendendo-a, resignificando-a.

Considerando a análise do segundo Memorial, verificou-se que emerge das narrativas dos licenciandos pistas de como suas identidades vêm sendo constituídas, em especial pela "influência dos professores", tido como modelos de sua formação; nas "práticas de estágio", que possibilitam a vivência da experiência docente; "dentro dos e nos discursos", que apresentam os professores que estão se tornando ou acreditam que vão se tornar; e, por atividades desenvolvidas na 
formação inicial, em que o Memorial tem sido um instrumento de reflexão e de formação dos licenciandos.

Portanto, acredita-se que por meio da produção dos Memoriais podemos, por um lado, compreender como os licenciandos estão se formando e constituindo sua identidade docente, que não se desassocia de sua identidade de sujeito, pois faz parte do ser professor; e por outro, a perceber a importância dos Memoriais para os licenciandos, pois a partir deles podem refletir sobre sua experiência de vida ao longo de sua formação, ressignificando-a e compreendendo como vem aos poucos se constituindo, se tornando professor.

\section{CONSIDERAÇÕES}

Considerando o instrumento de pesquisa utilizado, procurou-se analisar os licenciandos em sua trajetória de vida e seus percursos de formação, o que foi compreendido pela pesquisa como um "movimento" de análise para compreender o processo de constituição da identidade docente, do tornar-se, formar-se professor. Assim, buscou-se nesse movimento compreender como vem se constituindo a identidade docente emergida a partir da produção de Memoriais de Formação de licenciandos em Matemática da Universidade do Estado de Mato Grosso-(UNEMAT), Campus de Barra do Bugres-MT, a partir de um olhar cuidadoso e subjetivo sobre as suas narrativas nos Estágios I e II das turmas 2016/02 e 2017/01.

Dessa forma, o problema de pesquisa que se propôs resolver foi: "Como se constitui a Identidade Docente emergida a partir da produção de Memoriais de Formação de licenciandos em Matemática da Universidade do Estado de Mato Grosso-(UNEMAT), Campus de Barra do Bugres-MT, desenvolvidos durante os Estágios Curriculares Supervisionados I e II do período de 2016/2 e 2017/01?"

$\mathrm{Na}$ tentativa de buscar respostas à questão de investigação, a pesquisa tinha como objetivo investigar, na formação inicial de professores, o processo de constituição da identidade docente que emerge a partir da produção dos Memoriais de Formação dos licenciandos de Matemática da UNEMAT de Barra do Bugres - MT; desenvolvidos durante os Estágios Curriculares Supervisionados I e II, realizados no período de 2016/02 e 2017/01; no sentido de perceber que indícios podem ser encontrados nas narrativas autobiográficas da história de vida e formação, os Memoriais de Formação dos licenciandos, que revelam elementos importantes do processo de constituição da identidade docente dos futuros professores.

Assim, para responder estas inquietações, a pesquisa buscou pelos objetivos específicos, inicialmente: identificar nas narrativas escritas, as possíveis marcas/influências deixadas por professores; como estas marcas/influências estão sendo ressignificadas pelos licenciandos; e quais os elementos/momentos do processo de constituição da identidade docente que emergem a partir da produção dos Memoriais. E, em seguida buscamos analisar se os Memoriais de Formação podem ser instrumentos de reflexão do processo de formar-se professor, na perspectiva dos licenciandos.

No primeiro momento, percebeu-se que há muitas marcas e influências deixadas por professores, que, em alguns casos, estão sendo ressignificadas pelos 
licenciandos, e, em outros, ainda deixam traumas de formação no sujeito, que criam barreiras no seu processo de formação e aprendizagem. E, os elementos e momentos de constituição da identidade docente podem ser vistos pela influência da família, amigos, contexto social, o estágio, os discursos e práticas discursivas, pelo Memorial, e em especial os professores que são modelos do que os licenciandos querem ou não seguir, e que vão influenciando a formação dos licenciandos. Acredita-se que tal formação ocorre como um processo contínuo em que, aos poucos, os licenciandos vão se formando e se descobrindo professores, e que suas identidades não são fixas, mas vão sendo produzidas dentro dos e nos discursos e nas relações com os contextos do qual fazem parte.

Já com relação a compreender se os Memoriais de Formação podem ser instrumentos de reflexão do processo de formar-se professor, na perspectiva dos licenciandos, mediante todas as narrativas e análises realizadas, analisou-se que o Memorial tem exercido um potencial formativo importante nesse processo de formar-se, constituir-se professor, levando os licenciandos a refletirem sobre seus percursos de vida e formação, resignificando-os e os transformando, compreendendo melhor suas identidades.

Assim, compreendeu-se que com a escrita dos Memoriais os licenciandos estão conseguindo refletir sobre sua formação, vivendo e revivendo momentos que foram importantes em sua vida, e que esses momentos, em alguns casos, passam a ser vistos com outros olhares e a ter outros sentidos, outros significados. Compreendemos ainda que refletir e escrever os memoriais permite ao licenciando reviver o que foi esquecido e contribui com sua formação, fazendo com que esse sujeito compreenda melhor seu percurso formativo. Dessa forma, o Memorial pode ser compreendido como um instrumento para a reflexão da constituição da identidade docente dos licenciandos.

Nesse movimento, de investigar a produção dos Memoriais de Formação, o que emergiu das narrativas dos licenciandos é que os Memoriais foram instrumentos de reflexão da formação dos licenciandos e serviram para que os mesmos pudessem repensar a história de vida e formação; indicando ainda que os elementos influência da família, dos professores, dos amigos, do processo de educacional, dos contextos dos quais fazem ou fizeram parte, das práticas de estágio, dos discursos produzidos, e dos modelos de professores, contribuem para a constituição da identidade do sujeito que estão se constituindo, e que também fazem parte da identidade docente do professor, já que o professor é a pessoa e a pessoa é o professor, e assim, uma identidade não se dessassocia da outra, mas, se complementam. Assim, pode-se dizer que refletir sobre sua história de vida pode contribuir para reflexão da própria formação e constituição da identidade.

Acredita-se que os sinais que as narrativas estão apresentando, indicam algumas pistas de como a identidade dos licenciandos vai se constituindo, num processo de relação dos sujeitos com os discursos e contextos de sua história de vida e formação. Compreende-se, assim, que o Memorial pode ser um valioso instrumento utilizado no processo de formação e constituição da identidade docente dos licenciandos, que requer, por um lado, uma boa orientação por parte dos professores formadores, e por outro, um mergulho profundo, por parte do licenciando, na sua história de vida e formação, em busca de elementos que o formem e o transformem, mas que, acima de tudo, possibilitem a reflexão dos 
percursos vividos e do processo de formar-se professores de Matemática no qual estão se formando.

Portanto, considerou-se que as experiências vividas pelos sujeitos podem ser influenciadas por toda a história de vida e formação, nos contextos que fazem e fizeram parte e podem provocar mudanças em sua identidade, que não é fixa, mas que está em constante transformação. Assim, pode-se compreender que oportunizar aos futuros professores a reflexão sobre o seu processo de formação, por meio da escrita de Memoriais de Formação, pode ser um caminho para compreenderem esse processo de formação como fundamental na constituição do ser, do tornar-se, do formar-se, do constituir-se professor de Matemática. 


\title{
Writing the identity constitution of the Mathematical teacher narrated in the Memorial
}

\begin{abstract}
This work presents a research developed in Programa de Pós-Graduação Stricto Sensu em Ensino de Ciências e Matemática - PPGEM from Mato Grosso University - UNEMAT, Deputado Renê Barbour Campus, located in Barra do Bugres-MT municipality. The purpose of the research was to investigate the process of teacher identity formation, which emerged from the production of Formation Memorials of Mathematics Graduates from UNEMAT, Deputado Renê Barbour Campus, Barra do Bugres - MT ; developed during Supervised Curriculum I and II, developed in 2016/02 and 2017/01 periods. The methodology used was based on the qualitative approach, with an interpretive nature, adopting the (auto) biographical method, with emphasis on the narratives of life histories, having as an instrument of data production the Training Memorials produced by the graduates. This work was based on the theoretical contributions of authors who discuss themes related to teacher education, identity and memorial, such as Marcelo Garcia (1999), Larrosa (2002, 2004), Pimenta (1999, 2005), Fiorentini, Jaramillo (2003), Fiorentini e Castro (2003), Hall (2006), Silva, Woodward and Hall (2004), Nóvoa (1992, 2009, 2010), Nóvoa and Finger (2014), Passegi $(2006,2008)$, among others. The results of the analysis evidenced several elements in contact, influencing the constitution of the teaching identity of the researched licensees. Among them, we can highlight some, such as: family, friends, school, social contexts, teachers, university; the speeches produced by the graduates; marks (positive or negative) of training left by teachers etc. We conclude that the Memorial might be a valuable tool in the process of initial formation of graduates, and may contribute to the formation of reflexive subjects that understand their own process of forming teachers.
\end{abstract}

KEYWORDS: Initial Teacher Formation, Teaching Identity, Formation Memorial 


\section{AGRADECIMENTOS}

Agradecemos ao Programa de Pós-Graduação Stricto Sensu em Ensino de Ciências e Matemática -PPGEM, da Universidade do Estado de Mato Grosso-UNEMAT, Campus de Barra do Bugres-MT, aos professores que contribuíram como esta pesquisa, aos licenciandos que fizeram desta investigação e à família e amigos que fizeram parte desta caminhada.

\section{REFERÊNCIAS}

BOGDAN, R.ç BIKLEN, S. Investigação qualitativa em Educação. Uma introdução à teoria e aos métodos. Lisboa: Porto Editora, 1994.

HALL, S. Quem precisa de Identidade. In: SILVA, T. T. da. (Org.). Identidade e diferença: a perspectiva dos Estudos Culturais. 3a ed. Petrópolis/RJ: Vozes, 2004.

LARROSA, J. Notas sobre a experiência e o saber de experiência. Revista Brasileira de Educação, Rio de Janeiro, n. 19, p. 20-28, jan.-abr. 2002.

MARCELO GARCIA, C. A identidade docente: constantes e desafios. Revista Brasileira de Pesquisa sobre Formação Docente. Belo Horizonte, v. 1, n. 1, p.109131, ago.-dez. 2009.

MOITA, M. da C. Percursos de formação e de trans-formação. In: NÓVOA, A. (Org.). Vidas de professores. 2. ed. Porto: Porto Editora, 2007. p.111-140

NÓVOA, A. Formação de professores e profissão docente. In: NÓVO, A. (org). Os professores e a sua formação. Lisboa: Dom Quixote, 1992. p. 13-33

NÓVOA, A. A formação tem que passar por aqui: as histórias de vida no Projeto Prosalus. In: NÓVOA, A.; FINGER, M. (Org.). O método (auto)biográfico e a formação. Natal: EDUFRN; São Paulo: Paulus, 2014.

PASSEGGI, M. da C. A dimensão histórica do sujeito na formação docente. Natal: UFRN, 2003.

PASSEGGI, M. da C.; BARBOSA, T. M.N. (Org). Memoriais, memórias: pesquisa e formação docente. São Paulo: Paulus, Natal: EDUFRN, 2008. (vol.5)

PASSEGGI, M. da Co. Memoriais Auto-Biog-Gráficos: A arte profissional de tecer 
memórias: pesquisa e formação docente. São Paulo: Paulus, Natal: EDUFRN, 2008. (vol.5)

PASSEGGI, M. da C. Memorial de formação. In: OLIVEIRA, D.A.; DUARTE, A.M.C.; VIEIRA, L.M.F. DICIONÁRIO: trabalho, profissão e condição docente. Belo Horizonte: UFMG/Faculdade de Educação, 2010. CDROM

PORTUGAL, J. Grafias da vida, escritas de si: narrativas de professores de geografia em formação. In: MONTEIRO, F.A; NACARATO, Adair. M e FONTOURA, H. A. Narrativas docentes, memórias e formação. Curitiba: CRV, 2016

ROCHA, S. A. da; ANDRÉ, M. Os memoriais na licenciatura: narrativas dos entreespaços da formação docente, In: ROCHA, S. A. da (Org.). Formação de Professores: licenciaturas em discussão. Cuiabá: EDUFMT, 2010. p.77-89.

WOODWARD, K. Identidade e diferença: uma introdução teórica. In: SILVA, T. T. da. (Org.). Identidade e diferença: a perspectiva dos Estudos Culturais. 3 a ed. Petrópolis/RJ: Vozes, 2004.

Recebido: 10 nov. 2017

Aprovado: 21 mar. 2018

DOI: $10.3895 /$ actio.v3n1.7310

Como citar:

LIMA, V. S. A.; KOCHHANN, M. E. R. Tecendo a constituição identitária do professor de matemática narrado

nos memoriais. ACTIO, Curitiba, v. 3, n. 1, p. 184-204, jan./abr. 2018. Disponível em:

$<$ https://periodicos.utfpr.edu.br/actio>. Acesso em: XXX

Correspondência:

Vanessa Suligo Araújo Lima

Rua: Onze, casa 821, Jardim Imperial, Barra do Bugres, CEP 78390-000, Mato Grosso, Brasil.

Direito autoral: Este artigo está licenciado sob os termos da Licença Creative Commons-Atribuição 4.0

Internacional.

(c) (i) 